\title{
Volume 153: Editorial
}

We have sadly lost a member of our Editorial Board Ravi Sangakkara who tragically died on 29 August 2014 following a car accident. Ravi was a long-standing member of the Editorial Board for many years and will be sadly missed by colleagues, family and friends. A two-part obituary follows, the first part written by his colleagues at ETH where he was a guest lecturer, and the second by Professor Naylor, Senior Editor of this journal for crops and soils until July 2012 and who appointed him to the Editorial Board.

In the other news, there has been a slight fall in the number of submitted papers in 2014, but an increase in Impact Factor from the level of 1.691 in 2013. The number of submitted papers is likely to hit 600 by the end of the year, which is a slight fall on the record number submitted last year. As a result of the increased number of papers submitted and subsequently accepted, we have increased both the number of pages per issue (up to 192) and the number of issues per year (up to 8) in 2015.

Christine Watson relinquished her position on the Editorial Board at the end of 2014: we thank her for her excellent contribution to the journal over the last 5 years and wish her well for the future.

A number of new members have been appointed to the Editorial Board to accommodate the increasing volume of submitted papers and will be taking up their positions in 2015.

Hans-Peter Piepho-University of Hohenheim, Stuttgart, Germany;

Warshi Dandeniya - Faculty of Agriculture, University of Peradeniya, Sri Lanka;

Shabtai Bittman - Agriculture and Agri-Food Canada, British Columbia, Canada.

As always, we are indebted to our Editorial Board members and the many international reviewers who assist the Board by conducting detailed peer reviews. Without these willing volunteers, our task would be impossible and the continued success of the journal owes a lot to them. A list of those who have reviewed papers for us in 2014 is available at http://journals.cambridge.org/AGS

We look forward to a successful year in 2015 where we can continue to build upon the reputation that Journal of Agricultural Science, Cambridge has achieved over the last 109 years.

Paul Bilsborrow, Senior Crops and Soils Editor Julian Wiseman, Senior Animals Editor Alison Sage, Editorial Office Manager 